\title{
Comparison of Problematic Behavior Assessment by Physical and Occupational Therapists
}

\author{
Masayuki Uesugi, RPT ${ }^{1)}$, Susumu Naruse, RPT ${ }^{1)}$, Yuri Inoue, RPT ${ }^{1)}$, Tatsuya Yasukawa, \\ RPT $^{1)}$, Masahito Murakami, RPT ${ }^{1)}$, Seitchi Takemasa, RPT ${ }^{1)}$ \\ 1) Kobe International University: 9-1-6 Koyouchou, Higasinadaku, Kobe City, Hyogo 658-0032, Japan. \\ TEL: +81 78-845-3131,E-mail: uesgui@kobe-kiu.ac.jp
}

\begin{abstract}
Purpose] We used the Japanese version of the Aberrant Behavior Checklist (ABC-J) to investigate whether or not physical therapists (PT) and occupational therapists (OT) assess problematic behaviors of handicapped children differently. [Subjects] The subjects were 11 mentally-retarded children undergoing physical therapy at T Hospital. The examiners were classified into two groups: PT and OT. Wilcoxon's signed rank sum test was conducted on the two groups' ABC-J scores for, irritability, lethargy, stereotypy, hyperactivity and inappropriate speech scores. [Results] No significant differences between the two groups were observed for most problematic behavior types, although the effect sizes were small. Physical therapists, however, assessed the lethargy of the subject children as more problematic than occupational therapists did. [Conclusion] The results that some bias may occur depending on examiner occupation, although the ABC-J allows anyone to be an examiner as long as he/she knows the subject child well.
\end{abstract}

Key words: Assessment, Handicapped children, Aberrant Behavior Checklist

(This article was submitted Dec. 19, 2011, and was accepted Feb. 12, 2012)

\section{INTRODUCTION}

According to the Japanese Ministry of Health, Labour and Welfare, there are approximately 550,000 mentally-retarded (MR) people including 117,000 MR children in Japan, and approximately 420,000 live at home and 130,000 in institutions $\$$. The occurrence rate of MR children varies broadly from $0.86 \%$ to $5.6 \%$ depending on reports, but is quite high; generally 1 child out of 50 ( 2 to 3 per 100 births) is MR

Problematic behaviors include irritability, lethargy, stereotypy, hyperactivity, and inappropriate speech. and they could be factors which delay human motor development. Physical therapists often treat mentally-handicapped children as well as physically-handicapped children 1 . Physical therapists are required to increase their understanding of mental retardation $\$$, and physical therapy approaches are required to account for coexisting mental retardation $6-12$. In addition, cooperative approaches, in which different types of therapists work together treating children with disabilities, are required in pediatric rehabilitation ${ }^{-10}$. We suspected that different types of therapists might not share the same recognition of children's problematic behaviors. Therefore, we investigated whether or not physical therapists and occupational therapists assess problematic behaviors of handicapped children differently, when using the Japanese version of the Aberrant Behavior Checklist (ABC-J) $)^{13}$.

\section{SUBJECTS AND METHODS}

The subjects were 11 mentally-retarded children under- going physical therapy at T Hospital ( 7 boys and 4 girls, aged from 5 years and 6 months to 18 years and 1 month, with an average age of 11 years and 2 months \pm 4 years and 4 months) (Table 1). The subjects were diagnosed as having cerebral palsy (4 subjects), head injury aftereffects (1 subject), mental retardation (2 subjects) and acute encephalopathy aftereffects (4 subjects). The examiners were 8 physical therapists and 7 occupational therapists, 15 examiners in total, who worked at the hospital and knew the subject children well (Table 2). The physical therapists had 2 to 14 years of work experience (average: 3.7 years), and the occupational therapists had 2 to 24 years of work experience (average: 8.3 years). The examiners individually assessed the subjects using the ABC-J. The $\mathrm{ABC}$ is a questionnaire developed by Aman et al. for assessing problematic behaviors of mentally-handicapped persons. The ABC has been used by many studies, including studies of syndrome phenotypes and pharmacotherapy effects. The examiners were classified into two groups: physical therapist (PT) and occupational therapist (OT). Wilcoxon's signed rank sum test was conducted on the two groups' ABC-J score for irritability, lethargy, stereotypy, hyperactivity and inappropriate speech. Statistical analyses were conducted using $\mathrm{R}$ 2.8.1 software. The ABC-J questionnaire consists of 58 items in total: 15 irritability, 16 lethargy, 7 stereotypy, 16 hyperactivity, and 4 inappropriate speech items. The examiners who knew the subjects well answered each questionnaire item by giving a score of 0 to 3: 0 indicates not problematic, 1 indicates slightly problematic, 2 indicates problematic, and 3 indicates seriously problematic. The subjects' problematic 
Table 1. Characteristics of subjects

\begin{tabular}{|c|c|c|c|c|c|c|}
\hline Case & Diagnosis & Age & Sex & $\begin{array}{c}\text { GMFCS } \\
(\mathrm{I}-\mathrm{V})\end{array}$ & $\begin{array}{l}\text { Language } \\
\text { (4 stage) }\end{array}$ & $\begin{array}{c}\text { RyouikuTechou } \\
\text { (3 stage) }\end{array}$ \\
\hline 1 & Cerebral Palsy & $16 \mathrm{Y} 7 \mathrm{M}$ & male & III & Babbling & $\mathrm{A}$ \\
\hline 2 & Cerebral Palsy & $11 \mathrm{Y} 1 \mathrm{M}$ & male & I & Two word sentences & \\
\hline 3 & Cerebral Palsy, Mental Retardation & $15 \mathrm{Y} 2 \mathrm{M}$ & male & $\mathrm{V}$ & Two word sentences & \\
\hline 4 & Cerebral Palsy, Mental Retardation & $13 \mathrm{Y} 10 \mathrm{M}$ & female & $\mathrm{V}$ & Babbling & \\
\hline 5 & acute encephalopathy aftereffects & $18 Y 1 M$ & male & $\mathrm{V}$ & No verbal & \\
\hline 6 & acute encephalopathy aftereffects & $5 \mathrm{Y} 6 \mathrm{M}$ & female & III & Two word sentences & \\
\hline 7 & acute encephalopathy aftereffects & $9 \mathrm{YOM}$ & female & $\mathrm{V}$ & No verbal & A \\
\hline 8 & Mental Retardation & $6 \mathrm{Y} 4 \mathrm{M}$ & male & III & Two word sentences & \\
\hline 9 & head injury aftereffects & $14 \mathrm{Y} 8 \mathrm{M}$ & male & III & Two word sentences & \\
\hline 10 & Mental Retardation & $6 \mathrm{Y} 3 \mathrm{M}$ & female & III & Two word sentences & \\
\hline 11 & acute encephalopathy aftereffects & $6 \mathrm{Y} 7 \mathrm{M}$ & male & $\mathrm{V}$ & Babbling & \\
\hline
\end{tabular}

YM: represent year and month

Table 2. Characteristics of raters

\begin{tabular}{cccccc}
\hline PT & Sex & Years work experience & OT & Sex & Years work experience \\
\hline A & female & 7 & a & female & 10 \\
B & male & 2 & b & female & 2 \\
C & male & 2 & c & female & 11 \\
D & male & 2 & d & female & 2 \\
E & male & 2 & e & female & 2 \\
F & female & 2 & f & female & 24 \\
G & female & 14 & $\mathrm{~g}$ & female & 7 \\
H & female & 2 & & & \\
\hline
\end{tabular}

behaviors were assessed by recording the points on the score sheet.

We provided information about this study, in writing, to the parents of all subject children in advance of the research, and they all agreed that their children could be included in the research. This study was approved by the Kobe International University Ethical Committee (Approval No. G2011-015).

\section{RESULTS}

The significance of differences (p) between the PT and OT groups and their effect sizes were as follows: Irritability: $\mathrm{p}=0.4372, \mathrm{ES}=0.2500 ;$ Lethargy: $\mathrm{p}=0.0091, \mathrm{ES}=0.8037$; Stereotypy: $\mathrm{p}=0.3428, \mathrm{ES}=0.3161 ;$ Hyperactivity: $\mathrm{p}=$ $0.1953, \mathrm{ES}=0.4021 ;$ Inappropriate Speech $: \mathrm{p}=0.3991, \mathrm{ES}$ $=0.2845$. The results for lethargy were $5(0.5-5)$ as scored by the PT group and $10(2.5-12)$ scored by the OT group (median $(25 \%-75 \%)$

\section{DISCUSSION}

No significant differences between the two groups were observed for most problematic behavior types, although the effect sizes were small. In the ABC-J, questionnaire items are arranged randomly so that examiners cannot see which problematic behavior type a questionnaire item relates to.
Despite this, the two groups assessed questionnaire items related to lethargy differently $(\mathrm{p}=0.0091$, $\mathrm{ES}=0.8037)$. Physical therapists assessed the lethargy of the subject children as more problematic (average score: $8.1 \pm 7.8$ ) than occupational therapists did (average score: $3.8 \pm 4.8$ ). We previously studied the reliability of the ABC-J at pediatric facilities with operational and physical therapists as examiners 14 . In that study, the scores of some problematic behavior types were consistent and reliable between examiners, but the reliability of the lethargy scores was particularly low. The occupational therapists' average score was $0.3( \pm 0.5)$ whereas the physical therapists' average score was $3.2( \pm 8.9)$, showing a similar tendency to the results of the present research. Occupational therapists tend to observe children taking static postures, including sitting, whereas physical therapists tend to observe children when they are more active. This observational difference might explain why physical and occupational therapists assess lethargy as a problematic behavior differently . In addition, we also thought the length of work experience of OT group might have influenced the result. Our results suggest that some bias may occur depending on examiner occupation, although the ABC-J allows anyone to be an examiner as long as he/ she knows the subject child well. Our results also suggest that we must remember that the assessment of lethargy as a problematic behavior varies significantly depending on 
the therapist type. Although physical therapists and occupational therapists often treat the same children, we found no research literature on such differences between physical and occupational therapists in assessing problematic behaviors of child patients. This study is meaningful since it points out a problem in cooperative approaches, in which different types of therapists work together to treat children. This study is also a new and significant physical therapy study.

\section{REFERENCES}

1) Ministry of Health, Labour and Welfare: Basic Survey on Mentally Retarded Children and People, http://www.mhlw.go.jp/toukei/saikin/hw/ titeki/index.html (Accessed Dec.10, 2011).

2) Cabinet Office: White Paper on the Handicapped, Tokyo, 2009, p5.

3) Jinnai K, Ando N, Ito T: Rehabilitation Medicine for Children, Tokyo: Igakushoin, 2007, pp 319-320 (in Japanese)

4) Hanzawa N: Rehabilitation of Children - Coping with Clinical Condition and Life Stages, Tokyo: Kanehara Publishing, 2004, p 231 (in Japanese).

5) Tada T: Roles of Physical Therapists at schools for handicapped children.
Rigaku Ryoho J, 2009, 44: 417-425 (in Japanese).

6) Koike J: Current state and view of child's rehabilitation. Rigaku Ryoho J, 2003, 37: 363-371 (in Japanese).

7) Edited by Uner T: Latest Findings in Intellectual and Developmental Disabilities Research. Croatia. Inteck (in print).

8) Kurihara M: Pediatric Rehabilitation. Tokyo: Ishiyaku Publishing, 2006, pp 3-4 (in Japanese).

9) Edited by Inoue Tsurumi: Physical Treatment for Children.Tokyo: Miwa Shoten, 2010, p116 (in Japanese)

10) Edited by Senju H: Physical Therapy for Children 2nd edition. Kobe: Shinryo Bunko, 2007, pp 79-80.

11) Translated by Kajiura I, Suzuki T: Handling Young Children with Cerebral Palsy at Home, Version 3, Tokyo: Ishiyaku Publishing, 2006, p 8 (in Japanese).

12) Edited by Karen D, Christine I, Nicholas FT: Physiotherapy and occupational therapy for people with cerebral palsy, a problem-based approach to assessment and management. London: Mac Keith Press, 2010, p 25.

13) Aman MG, Singh NN (Ono Y): Japanese manuals of Aberrant Behavior Checklist. Tokyo: Jiho, 2006 (in Japanese)

14) Uesugi M, Naruse S, Inoue $Y$, et al.: The reliability of the Japanese manuals for the Aberrant Behavior Checklist in daycare center for handicapped children. J Phys Ther Sci, 2010, 22: 57-59. [CrossRef] 